\title{
Effects of Biochar on Waterlogging and the Associated Change in Micro-ecological Environment of Maize Rhizosphere Soil in Saline-alkali Land
}

\author{
Zhihui Wang, Dawei Yin, Hongyi Wang, Changjiang Zhao, and Zuotong Li* \\ Saline-alkali soils of northern China are prone to waterlogging after \\ degradation caused by overuse. The effects of biochar (40 t/ha) were \\ tested relative to the physico-chemical properties of maize rhizosphere \\ soil, the composition and function of the soil bacterial community, and its \\ response to sudden waterlogging. Biochar treatment decreased the $\mathrm{pH}$ \\ and bulk density of the soil and increased soil organic carbon (SOC), \\ available nitrogen (AN), and available phosphorus (AP). The relative \\ abundance of bacteria (Proteobacteria, Actinobacteria, Bacteroidetes, and \\ Nitrospirae) also increased, along with the activities of soil enzymes, such \\ as dehydrogenase, $\beta$-glucosidase, and alkaline phosphomonoester. The \\ response of soil microbial enzymes to biochar addition was induced by \\ changes in the soil physical properties $(\mathrm{pH}$, soil moisture content, and soil \\ respiration $(\mathrm{BR}))$. Changes in the bacterial community structure were \\ driven by soil nutrients and physical characteristics (AN, AP, SOC, $\mathrm{pH}$, \\ moisture, water-stable aggregate stability rate, BR, and bulk density). After \\ waterlogging, soil with biochar demonstrated high water permeability and \\ improved soil respiration. The relative abundance of soil bacteria and \\ enzyme activities remained higher in the biochar plot than in the no- \\ biochar plot. Biochar maintained the growth and vitality of maize roots in \\ unfavorable environmental conditions, thus ensuring high yields.
}

Keywords: Biochar; Saline-alkali soil; Soil bacteria; Maize yield; Available nitrogen; Soil organic carbon

Contact information: College of Agronomy, Heilongjiang Bayi Agricultural University/Key Laboratory of Modern Agricultural Cultivation and Crop Germ-plasm Improvement of Heilongjiang Province, Daqing 163319, Heilongjiang, China; *Corresponding author: lxg64019@163.com

\section{INTRODUCTION}

Heilongjiang is a key grain production base in China with maize (Zea mays L.) as its main food crop. However, the overuse of the cultivated land over successive years has caused severe salinization and compaction of the soil, erosion of the cultivation layer, degradation of the physico-chemical properties of the soil, and a reduction in soil microbial activity (Chen et al. 2020). With the frequent occurrence of extreme climate events in recent years, Heilongjiang has suffered from successive flooding and waterlogging disasters. Waterlogging is a natural disaster caused by excessive precipitation and the flooding of farmland. Consequently, the soil becomes saturated with water, adversely affecting the growth and production of maize. Waterlogging often occurs from July to September in the northern maize cultivation regions (Zhu et al. 2019). Waterlogging results in increased soil viscosity and poor permeability, where the soil water content is too high and air is squeezed out, leading to a lack of oxygen in the soil, reduced soil respiration and survival or reproduction of soil microorganisms, in addition to impaired crop growth (Wang et al. 1993). These factors have a strong impact on the stability and productivity of 
agricultural ecosystems (Wang et al. 2018). Finding a way in which to improve and stabilize the soil structure; recover the physico-chemical properties of the soil; create a benign micro-ecological environment in farmland soil; and ultimately improve the maize yield, has become an urgent issue.

In recent years, the use of biochar for improving soil conditions and crop production has attracted wide interest. Biochar is a stable, high-carbon product obtained through the pyrolysis of agricultural waste biomass under low-oxygen or oxygen-free conditions (Meng et al. 2019). It exhibits a loose and porous structure along with a high specific surface area. The application of biochar in the soil serves several functions including improving soil structure; reducing bulk density; regulating soil water, temperature, and gas conditions; and increasing soil nutrients such as nitrogen, phosphorus and potassium (Lehmann et al. 2009; Fan et al. 2020). In addition, the application of biochar is known to change the composition and community structure of soil microorganisms (Quilliam et al. 2013). Jiang (2016) applied biochar in a corn field in brown soil and examined the effects after three years, finding that the presence of biochar significantly increased the abundance of Proteobacteria, Actinobacteria, Acidobacteria, Bacillus, Chloroflexi, and Nitrospira in the soil and reduced the relative abundance of Planctomycetes and Bacteroidetes. These changes were closely related to the nutrient content of the soil. Yao (2017) has also demonstrated significant improvements in the bacterial abundance of black soil with corn/soybean rotations in Northeast China after applying biochar for over three years. The improvement was attributed to the gradual change in the soil physical habitat. In particular, the change of the bacterial community structure was best explained by the change in soil properties. However, Guo (2018) analyzed the bacterial community in black soil corn fields after applying biochar for a short time and found that the increased abundance of Proteobacteria, Actinobacteria, and Bacteroidetes was positively related to the changes in nitrogen and cellulase in the soil. As demonstrated by their study, the composition and structure of soil bacterial communities with different properties will be affected differently by biochar under different driving factors. Nevertheless, there are only a limited number of studies on the soil of corn fields in saline-alkali land in cold regions. In a prolonged experiment on this topic, applying biochar at a rate of $40 \mathrm{t} / \mathrm{ha}$ provided the optimal performance in improving the properties of saline-alkali soils and increasing the soil nutrient content, both of which increased the maize yield effectively and economically (Wang et al. 2019). However, the underlying mechanisms of how biochar affects the composition, community structure, and function of corn field soil bacteria for achieving improved maize yields in saline-alkali land in cold regions still requires more systematic research. In particular, research is required to probe the synergistic changes found in biochar and soil for resisting unfavorable environmental changes after the occurrence of extreme climate events (e.g., waterlogging).

In this study, field plot experiments were conducted on saline-alkali land in the cold regions of Heilongjiang to investigate the effects of biochar addition (40 t/ha) on the physico-chemical properties of rhizosphere soil, as well as the structure and function of the soil bacterial community in saline-alkali maize fields. The effects of biochar addition on the micro-ecological environment in the rhizosphere soil of corn fields suffering from waterlogging during grain filling and the subsequent impact on the growth and yield of maize were also investigated in the study.

Two hypotheses were proposed: (1) Biochar is an effective way to resolve the farming issues associated with saline-alkali land in cold regions. By regulating the soil environment, biochar can facilitate changes in the composition, abundance, structure, and 
function of the soil microbial community. These changes will affect the series of biochemical reactions that occur in the soil, which in turn affects the growth and yield of plants; (2) the addition of biochar can keep the structure and properties of the soil relatively stable after waterlogging, with enhanced stress tolerance. Therefore, stable habitats can be provided to support the survival of soil microorganisms and the growth of plant roots, both of which will ensure that plants grow properly.

\section{EXPERIMENTAL}

\section{Test Location and Varieties}

The test was performed in 2019 at the experimental base in Heilongjiang Bayi Agricultural University $\left(46^{\circ} 37^{\prime} \mathrm{N} 125^{\circ} 11^{\prime} \mathrm{E}\right.$, altitude $\left.=146 \mathrm{~m}\right)$ in Daqing, Heilongjiang, China. The maize variety used for testing was Xianyu 335 with a growing season ranging from May to October. Figure 1 shows the temperature and precipitation information for the test region in the study period.

The minimum daily average temperature, maximum monthly average temperature, and total precipitation were $6.3{ }^{\circ} \mathrm{C}, 24.7{ }^{\circ} \mathrm{C}$, and $512.7 \mathrm{~mm}$, respectively. The total precipitation from July 5th to September 5th was $349.2 \mathrm{~mm}$. According to the data collected in the test area, the annual average precipitation over the past 10 years was 427 $\mathrm{mm}$. The total precipitation in 2019 was $20 \%$ higher than the average. In particular, the test area suffered through waterlogging because of multiple heavy rainfalls between the jointing stage of maize in July and the grain filling stage in September.

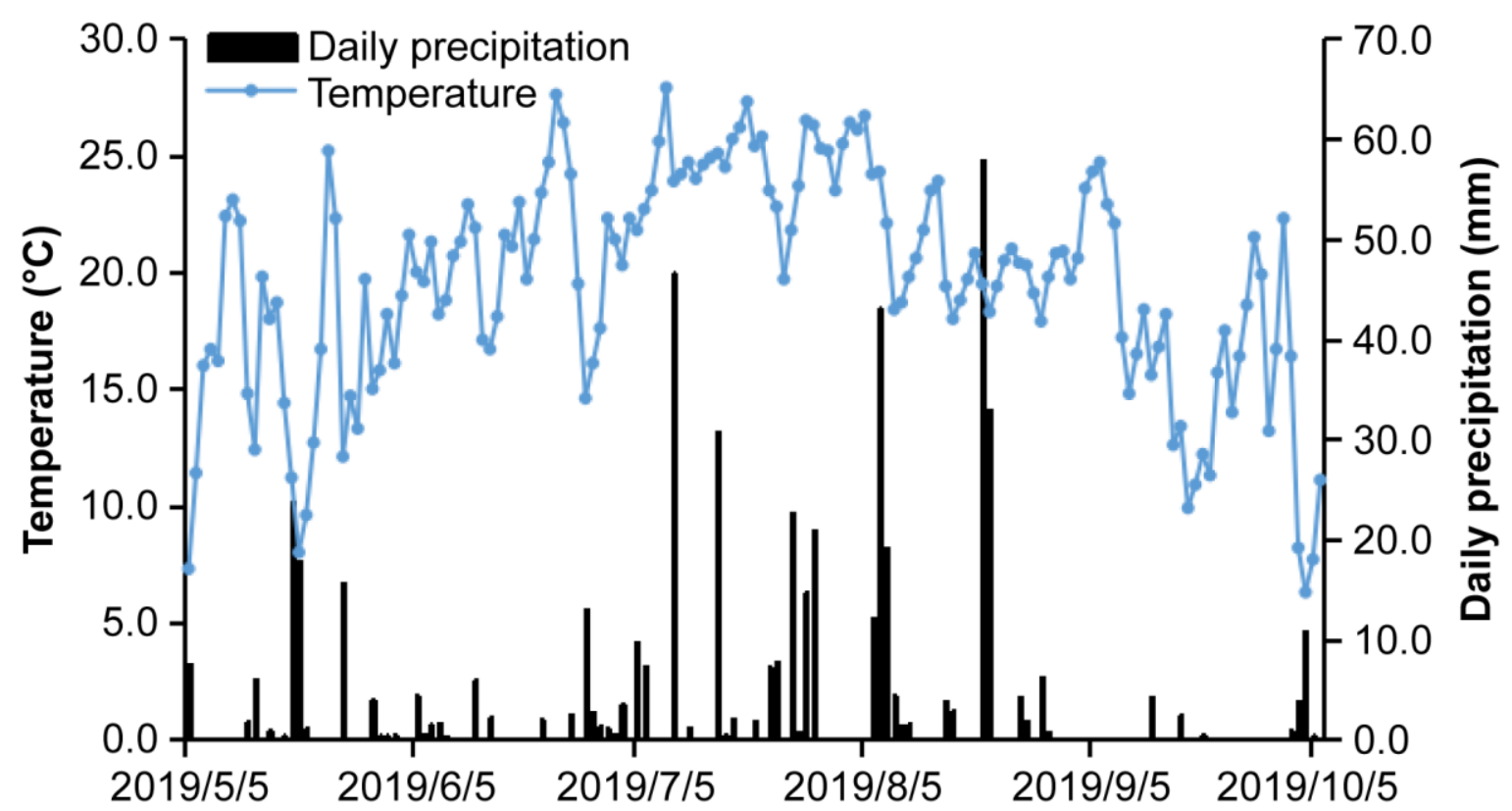

Fig. 1. Temperature and precipitation data for the test area during the growing season from May to October 2019

\section{Test Material and Experimental Design}

Saline-alkali soil was used as the test soil. The basic fertility information of the plough layer ( 0 to $20 \mathrm{~cm}$ ) includes a $\mathrm{pH}$ of 8.32, an organic matter content of $26.37 \mathrm{~g} / \mathrm{kg}$, an alkaline hydrolyzable nitrogen content of $128.65 \mathrm{mg} / \mathrm{kg}$, a rapidly available phosphorus 
content of $13.05 \mathrm{mg} / \mathrm{kg}$, and a rapidly available potassium content of $139.18 \mathrm{mg} / \mathrm{kg}$. The biochar used in the test was corn stalk charcoal purchased from Shenyang Longtai Biological Engineering Co., Ltd. (Shenyang, China). The raw material for pyrolysis was maize straw (Shibin 338). The pyrolysis conditions were $400^{\circ} \mathrm{C}$ for $1.5 \mathrm{~h}$, and the detailed charring method can be found in the Chinese patent CN 102092709 B (Chen 2012). The basic physico-chemical properties of the biochar included a $\mathrm{pH}$ of 8.7, an organic carbon content of $582.4 \mathrm{~g} / \mathrm{kg}$, a total nitrogen content of $8.42 \mathrm{~g} / \mathrm{kg}$, a total phosphorous content of $8.15 \mathrm{~g} / \mathrm{kg}$, and a total potassium content of $29.6 \mathrm{~g} / \mathrm{kg}$.

Biochar was applied to the surface of the test soil once before preparing and ploughing the land. Subsequently, the biochar was spread evenly over the test area manually and uniformly mixed with the topsoil $(0$ to $20 \mathrm{~cm})$ using a rotary tiller. The samples were collected in the second year after biochar addition. The test field treated with biochar (40 t/ha) was denoted as B. In this study, another test field with no added biochar was used as the control and denoted as $\mathrm{C}$. Each treatment was replicated three times. Each test plot contained six rows and each row was $15 \mathrm{~m}$ long. The total area of the test plot was $58.5 \mathrm{~m}^{2}$. Maize was cultivated in the test plot by ridge planting with a uniform ridge spacing of $0.65 \mathrm{~m}$. The total planting density was 75,000 plants/ha. Urea with $46 \%$ nitrogen $(\mathrm{N})$, diammonium phosphate with $46 \%$ phosphorus pentoxide $\left(\mathrm{P}_{2} \mathrm{O}_{5}\right)$, and potassium sulfate with $50 \%$ potassium oxide $\left(\mathrm{K}_{2} \mathrm{O}\right)$ were applied as fertilizers in the field at concentrations of $164.5 \mathrm{~kg} / \mathrm{ha}, 120 \mathrm{~kg} / \mathrm{ha}$, and $90 \mathrm{~kg} / \mathrm{ha}$, respectively. Around $70 \%$ of the urea, along with all of the diammonium phosphate and potassium sulfate, were applied to the field as a base fertilizer once during the sowing process. The remaining $30 \%$ of urea was applied in the field as top dressing during the jointing stage. All other field management measures were carried out in accordance with the standard high-yield maize cultivation procedures.

\section{Sample Collection}

The test samples were collected in two batches. The first batch, denoted as M7, was collected at the jointing stage of maize (July $5^{\text {th }}$ ). The second batch, denoted as M9, was collected at the grain filling stage (September $5^{\text {th }}$ ) after the occurrence of waterlogging. During sampling, five plants of similar growth status were randomly selected from each treatment plot. The biomass of the above-ground plant, the growth characteristics of the roots, the physico-chemical properties of the soil, the enzyme activity of the soil, and the microbial diversity of the soil were analyzed.

The underground roots and soil of selected plants were collected for examination. A $40 \mathrm{~cm} \times 30 \mathrm{~cm}$ rectangular area based on the center line between adjacent plants was used as the root sampling region. The depth of the sampling region was around $50 \mathrm{~cm}$. A mixture of five soil samples collected at a depth of 0 to $20 \mathrm{~cm}$ was used for the rhizosphere soil sampling (Fu et al. 2018). The soil samples were sieved through a 2-mm mesh. Then, rhizosphere soil samples were collected in sterile zip-lock bags after removing large particles, broken roots, and stones using a dry sterile brush. The root samples were placed in a mesh bag. Finally, these samples were placed in an incubator with an ice box and transported to the laboratory. Each soil sample was divided into three portions. The first portion was placed in a sterile centrifuge tube and stored in a refrigerator at $-80{ }^{\circ} \mathrm{C}$ for measuring the soil microbial diversity. The second portion was stored at $4{ }^{\circ} \mathrm{C}$ for analyzing soil respiration and soil enzyme activity. The last portion was placed in a cloth bag and airdried in the laboratory for determining the physico-chemical properties of the soil. 


\section{Sample Examination}

Measuring physico-chemical properties and enzyme activity of the soil

The $\mathrm{pH}$ value of the soil was measured using a glass electrode with a soil-water ratio of 2.5:1 (Laboratory of Soil Physics 1978). The soil bulk density was measured by the ring knife method (Laboratory of Soil Physics 1978). The moisture content in the soil was determined by dehydrating a fresh soil sample $(10 \mathrm{~g})$ at $105{ }^{\circ} \mathrm{C}$ for over $24 \mathrm{~h}$ (Laboratory of Soil Physics 1978). The soil respiration was measured by the sodium hydroxide absorption and hydrochloric acid titration method (Laboratory of Soil Physics 1978). The water-stable aggregate stability rate (WSAR) of the soil was calculated based on the mass of $>0.25$-mm water-stable aggregates (wet sieving method) and the mass of $>0.25$-mm force-stable aggregates (dry sieving method) (Li 2017).

Soil organic carbon (SOC) was measured using the potassium dichromate oxidation method (Bao 2000). The effective nitrogen was measured using the diffusion absorption method based on sodium hydroxide hydrolysis and hydrochloric acid titration (Bao 2000). The soil available phosphorus (AP) was measured by means of $\mathrm{NaHCO}_{3}$ extractionammonium molybdate-tartaric emetic-ascorbic acid colorimetry (Bao 2000).

The soil dehydrogenase activity (DHA) was first extracted using a Solarbio BC0390 kit (Beijing, China), and then measured using spectrophotometer colorimetry. The soil $\beta$-glucosidase (BG) was extracted using a Solarbio BC0160 kit and measured using spectrophotometer colorimetry. The soil N-acetyl-glucosaminidase (NAG) was extracted using a Solarbio BC4000 kit and then measured using spectrophotometer colorimetry. The alkaline phosphomonoester (PME) was measured by the phosphate disodium colorimetry method (Guan 1986).

\section{Analysis of the maize root system and maize plant}

The root sample was first soaked in a sink with three layers of gauze placed at the bottom. The sample was then rinsed with running water continuously until the soil was completely separated from the roots. Finally, the fine roots were collected from the gauze. The root activity was determined by the 2,3,5-triphenyltetrazolium chloride method using certain root samples. The root biomass and plant biomass were determined by first blanching the root sample and above-ground plant at $105{ }^{\circ} \mathrm{C}$ for $30 \mathrm{~min}$, and then dehydrating it at $75^{\circ} \mathrm{C}$ for $48 \mathrm{~h}$ until the mass became constant. The maize yield was determined during harvesting on October $9^{\text {th }}, 2019$.

\section{High-Throughput Sequencing Analysis of Soil Bacterial Communities}

The soil samples analyzed were the rhizosphere soil samples described in the "Sample Collection" section. The analysis proceeded as described below.

\section{DNA extraction and PCR amplification}

The genomic DNA was extracted from $0.5 \mathrm{~g}$ of fresh soil using the MoBio PowerSoil DNA Isolation Kit (QIAGEN Inc., USA), following the manufacturer's instructions. The quality of DNA extracted was checked by $1 \%$ agarose gel electrophoresis and determined by NanoDrop 2000 UV-vis spectrophotometer (Thermo Scientific, Wilmington, USA). To assess the bacterial community composition, the V3-V4 region of the bacterial 16S rRNA gene was amplified by PCR $\left(3\right.$ min of denaturation at $95{ }^{\circ} \mathrm{C}, 27$ cycles of $30 \mathrm{~s}$ at $95{ }^{\circ} \mathrm{C}, 30 \mathrm{~s}$ for annealing at $55^{\circ} \mathrm{C}$, and $45 \mathrm{~s}$ for elongation at $72{ }^{\circ} \mathrm{C}$, and a final extension at $72{ }^{\circ} \mathrm{C}$ for $10 \mathrm{~min}$ ), using the universal primers forward $338 \mathrm{~F}$ (5'ACSOCCTACGGGAGGCAGCAG-3') and reverse 806R (5'-GGACTACHVGGGTWS- 
OCTAAT-3'). The $20 \mu \mathrm{L}$ PCR reaction mixtures consisted of $4 \mu \mathrm{L}$ of $5 \times$ FastPfu Buffer, $2 \mu \mathrm{L}$ of $2.5 \mathrm{mM}$ dNTPs, $0.8 \mu \mathrm{L}$ of each primer $(5 \mu \mathrm{M}), 0.4 \mu \mathrm{L}$ of FastPfu Polymerase, and $10 \mathrm{ng}$ of template DNA and finally ddH2O up to $20 \mu \mathrm{L}$. The PCR products were purified using the AxyPrep DNA Gel Extraction Kit (Axygen Biosciences, Union City, CA, USA) and quantified using QuantiFluor ${ }^{\mathrm{TM}}$-ST (Promega, USA) following the manufacturer's instructions.

\section{Illumina MiSeq sequencing}

Purified amplicons were pooled in equimolar and paired-end sequenced $(2 \times 300)$ on an Illumina MiSeq platform (Illumina, San Diego, USA) according to the standard protocols by Majorbio Bio-Pharm Technology Co., Ltd. (Shanghai, China).

\section{Processing of sequencing data}

Raw fastq files were quality-filtered by Trimmomatic and merged by FLASH with the following criteria: (i) the reads were truncated at any site receiving an average quality score $<20$ over a 50 bp sliding window; (ii) sequences whose overlap was longer than 10 bp were merged according to their overlap with a mismatch of no more than $2 \mathrm{bp}$; (iii) sequences of each sample were separated according to barcodes (exactly matching) and primers (allowing 2 nucleotide mismatching), and reads containing ambiguous bases were removed.

Operational taxonomic units (OTUs) were clustered with a $97 \%$ similarity cutoff using UPARSE (version $7.1 \mathrm{http} / /$ drive5.com/uparse/) with a novel 'greedy' algorithm that performs chimera filtering and OTU clustering simultaneously. The taxonomy of each $16 \mathrm{~S}$ rRNA gene sequence was analyzed by RDP Classifier algorithm (http://rdp.cme.msu.edu/) against the Silva (SSU123) 16S rRNA database using a confidence threshold of $70 \%$.

\section{Data Analysis}

Data are presented as the mean and standard deviation (SD) of the mean using Excel 2013 software (Microsoft, Redmond, WA, USA). One-way analysis of variance (ANOVA) was performed to determine the statistical significance $(\mathrm{p}<0.05 ; \mathrm{n}=3)$ of the treatment effects using IBM SPSS Statistics 21.0 software (Armonk, NY, USA). Least significant difference (LSD) was used to identify significant differences in soil bacterial relative abundance and soil enzyme activity. Duncan's new multiple range tests were used to analyze the physical and chemical properties of soil and plant characteristics. Significant differences in grain filling rate and yield between different treatments was identified using a Paired t test in GraphPadPrism7 (GraphPad Software, San Diego, CA, USA). Correlations between the microbial groups, enzyme activities, and soil physical and chemical properties, plant character were determined using a Pearson's correlation analysis. To illustrate the effects of biochar addition on the microbial community composition (using the bacterial phylum data), a redundancy analysis (RDA) was performed using Canoco software (Canoco for Windows 4.5, Biometris - Plant Research International, Wageningen, Netherlands). After standardizing the data, Monte Carlo permutation tests $(n=499)$ were used to evaluate the contribution and significance of different soil variables to the variation in the overall microbial community composition and enzymatic activity patterns. Results were statistically significant when $\mathrm{P}<0.05$. 


\section{RESULTS AND DISCUSSION}

\section{Response of Maize Rhizosphere Soil Properties and Plant Traits to Biochar Addition}

Compared to treatment $\mathrm{C}$, treatment $\mathrm{B}$ provided reduced soil $\mathrm{pH}$, lower bulk density, and higher soil organic carbon (SOC), available nitrogen (AN), available phosphorus (AP) content, and WSAR for samples collected at both M7 and M9 periods (Table 1).

Table 1. Effects of Biochar Addition on Soil Physico-Chemical Characteristics and Plant Variables

\begin{tabular}{|c|c|c|c|c|c|c|c|}
\hline Period & $\begin{array}{l}\text { Treat- } \\
\text { ment }\end{array}$ & $\mathrm{pH}$ & $\begin{array}{l}\text { Moisture } \\
(\%)\end{array}$ & $\begin{array}{l}\text { Bulk density } \\
\left(\mathrm{g} / \mathrm{cm}^{3}\right)\end{array}$ & $\begin{array}{c}\text { WSAR } \\
(\%)\end{array}$ & $\begin{array}{c}\mathrm{BR} \\
\left(\mathrm{mg} \mathrm{CO}_{2} \mathrm{~kg}^{-1}\right. \\
\left.\text { soil } \cdot \mathrm{d}^{-1}\right)\end{array}$ & $\frac{\mathrm{SOC}}{\left(\mathrm{g} \mathrm{kg}^{-1}\right)}$ \\
\hline \multirow{2}{*}{ M7 } & C & $\begin{array}{c}8.40 \\
\pm 0.01 \mathrm{a}\end{array}$ & $\begin{array}{c}20.14 \\
\pm 0.61 \mathrm{c}\end{array}$ & $\begin{array}{c}1.10 \\
\pm 0.06 \mathrm{bc}\end{array}$ & $\begin{array}{r}85.18 \\
\pm 0.96 \mathrm{~b}\end{array}$ & $\begin{array}{l}187.61 \\
\pm 5.17 a\end{array}$ & $\begin{array}{c}13.69 \\
\pm 0.57 \mathrm{bc}\end{array}$ \\
\hline & B & $\begin{array}{r}8.32 \\
\pm 0.01 \mathrm{~b} \\
\end{array}$ & $\begin{array}{c}20.91 \\
\pm 1.03 \mathrm{c} \\
\end{array}$ & $\begin{array}{c}1.07 \\
\pm 0.02 \mathrm{c} \\
\end{array}$ & $\begin{array}{r}88.55 \\
\pm 1.43 \mathrm{a} \\
\end{array}$ & $\begin{array}{c}170.01 \\
\pm 6.90 \mathrm{ab} \\
\end{array}$ & $\begin{array}{r}15.72 \\
\pm 0.70 \mathrm{a} \\
\end{array}$ \\
\hline \multirow{2}{*}{ M9 } & C & $\begin{array}{r}8.38 \\
\pm 0.01 \mathrm{a} \\
\end{array}$ & $\begin{array}{r}25.15 \\
\pm 0.51 \mathrm{a} \\
\end{array}$ & $\begin{array}{c}1.37 \\
\pm 0.06 \mathrm{a} \\
\end{array}$ & $\begin{array}{r}78.62 \\
\pm 0.53 \mathrm{c} \\
\end{array}$ & $\begin{array}{r}120.82 \\
\pm 5.73 \mathrm{c} \\
\end{array}$ & $\begin{array}{r}12.13 \\
\pm 0.42 \mathrm{c} \\
\end{array}$ \\
\hline & B & $\begin{array}{c}8.31 \\
\pm 0.01 \mathrm{~b} \\
\end{array}$ & $\begin{array}{r}22.86 \\
\pm 0.49 \mathrm{~b} \\
\end{array}$ & $\begin{array}{c}1.23 \\
\pm 0.01 \mathrm{~b} \\
\end{array}$ & $\begin{array}{r}84.30 \\
\pm 0.84 \mathrm{~b} \\
\end{array}$ & $\begin{array}{l}157.48 \\
\pm 6.73 \mathrm{~b}\end{array}$ & $\begin{array}{r}15.11 \\
\pm 0.52 \mathrm{ab} \\
\end{array}$ \\
\hline
\end{tabular}

\begin{tabular}{|c|c|c|c|c|c|c|}
\hline Period & $\begin{array}{l}\text { Treat- } \\
\text { ment }\end{array}$ & $\begin{array}{c}\text { AN } \\
\left(\mathrm{mg} \mathrm{kg}^{-1}\right)\end{array}$ & $\begin{array}{c}\mathrm{AP} \\
\left(\mathrm{mg} \mathrm{kg}^{-1}\right)\end{array}$ & $\begin{array}{l}\text { Root biomass } \\
\text { (g) }\end{array}$ & $\begin{array}{l}\text { Root activity } \\
\left(\mathrm{mg} \mathrm{g}^{-1} \mathrm{~h}^{-1}\right)\end{array}$ & $\begin{array}{c}\text { Maize biomass } \\
(\mathrm{g})\end{array}$ \\
\hline \multirow{2}{*}{ M7 } & C & $\begin{array}{l}145.13 \\
\pm 3.82 \mathrm{~b}\end{array}$ & $\begin{array}{r}13.86 \\
\pm 0.65 b\end{array}$ & $\begin{array}{c}6.07 \\
\pm 0.29 c\end{array}$ & $\begin{array}{r}51.60 \\
\pm 4.37 \mathrm{~b}\end{array}$ & $\begin{array}{r}23.88 \\
\pm 1.97 \mathrm{c}\end{array}$ \\
\hline & B & $\begin{array}{l}164.73 \\
\pm 3.99 \mathrm{a}\end{array}$ & $\begin{array}{c}17.12 \\
\pm 0.56 \mathrm{a} \\
\end{array}$ & $\begin{array}{c}7.78 \\
\pm 0.55 \mathrm{c} \\
\end{array}$ & $\begin{array}{c}67.77 \\
\pm 1.91 \mathrm{a} \\
\end{array}$ & $\begin{array}{r}31.98 \\
\pm 4.53 \mathrm{c} \\
\end{array}$ \\
\hline \multirow{2}{*}{ M9 } & C & $\begin{array}{l}120.87 \\
\pm 9.50 \mathrm{c} \\
\end{array}$ & $\begin{array}{c}7.82 \\
\pm 0.13 d \\
\end{array}$ & $\begin{array}{r}21.14 \\
\pm 1.12 \mathrm{~b} \\
\end{array}$ & $\begin{array}{r}41.82 \\
\pm 1.83 \mathrm{c} \\
\end{array}$ & $\begin{array}{l}334.53 \\
\pm 6.51 \mathrm{~b} \\
\end{array}$ \\
\hline & B & $\begin{array}{r}152.33 \\
\pm 2.84 a b\end{array}$ & $\begin{array}{c}11.62 \\
\pm 0.91 \mathrm{c}\end{array}$ & $\begin{array}{c}28.20 \\
\pm 1.26 \mathrm{a}\end{array}$ & $\begin{array}{c}58.57 \\
\pm 1.95 \mathrm{~b}\end{array}$ & $\begin{array}{l}417.78 \\
\pm 6.70 \mathrm{a}\end{array}$ \\
\hline
\end{tabular}

Note: Different letters indicate significant differences (one-way ANOVA, $P<0.05$, Duncan's multiple range test).

These findings suggested that the biochar addition altered the properties of the saline-alkali soil. For the samples collected during the M9 period (after waterlogging), treatment B provided significantly lower soil moisture content and higher soil respiration (BR) than treatment $\mathrm{C}$. This result suggested that the saline-alkali soil containing biochar exhibited better drainage functions and less inhibited respiration performance. Comparing the change in indicators from samples collected from the M7 and M9 periods, the soil $\mathrm{pH}$, WSAR, and BR were reduced by $0.24,7.70$, and $35.60 \%$, respectively, by treatment C; and by $0.12,4.80$, and $7.37 \%$, respectively, by treatment B. The soil moisture content and bulk density increased by $24.87 \%$ and $24.55 \%$, respectively, in treatment C; and by $9.33 \%$ and $14.95 \%$, respectively, in treatment B. 
These results indicated that the physical properties of the soil treated with biochar addition were less prone to variation, and the corresponding soil structure became more stable. A similar trend was observed in soil nutrient content. Comparing samples collected from the M9 and M7 periods, it was found that treatment $C$ provided 11.40, 16.72, and 43.58\% lower SOC, AN, and AP content, respectively, whereas treatment B provided 3.88, 7.53, and 32.13\% lower SOC, AN, and AP content, respectively. Nutrient content of the control soil decreased after waterlogging, but the nutrients of the soil with biochar decreased slightly, indicating that the addition of biochar alleviated the loss of soil nutrients.

For samples collected from the M7 period, treatment B showed a significant improvement in the root activity compared to treatment $\mathrm{C}$. For samples collected from the M9 period, however, treatment B was found to enhance root biomass, root activity, and maize biomass more than treatment $\mathrm{C}$. The root system and growth of maize were inhibited severely after waterlogging. However, the biomass of the above-ground and underground parts of maize grown with biochar addition remained at a high level and were substantially better than those from the control group.

\section{Response of Grain-filling Rate and Yield of Maize to Biochar Addition}

The grain-filling condition of maize was analyzed at $21 \mathrm{~d}$ and $56 \mathrm{~d}$ after silking. The grain-filling rate of samples with treatment B was significantly higher than that with treatment $\mathrm{C}$. With the progression of the fertility process, the grain-filling rate of the samples with treatment B increased steadily until it reached its peak value at $28 \mathrm{~d}$, after which it started to decrease slowly. However, the grain-filling rate of the samples with treatment $\mathrm{C}$ grew more slowly in the early stage and decreased suddenly after reaching the peak value. In particular, the grain-filling of the maize samples collected from period M9 in the control group almost stopped completely because of the waterlogging. The biochar addition significantly alleviated growth suppression so that the grain-filling in maize progressed smoothly. The difference in the grain-filling performance had a substantial impact on maize yield. Treatment B provided a significantly higher maize yield than treatment C (Fig. 2).
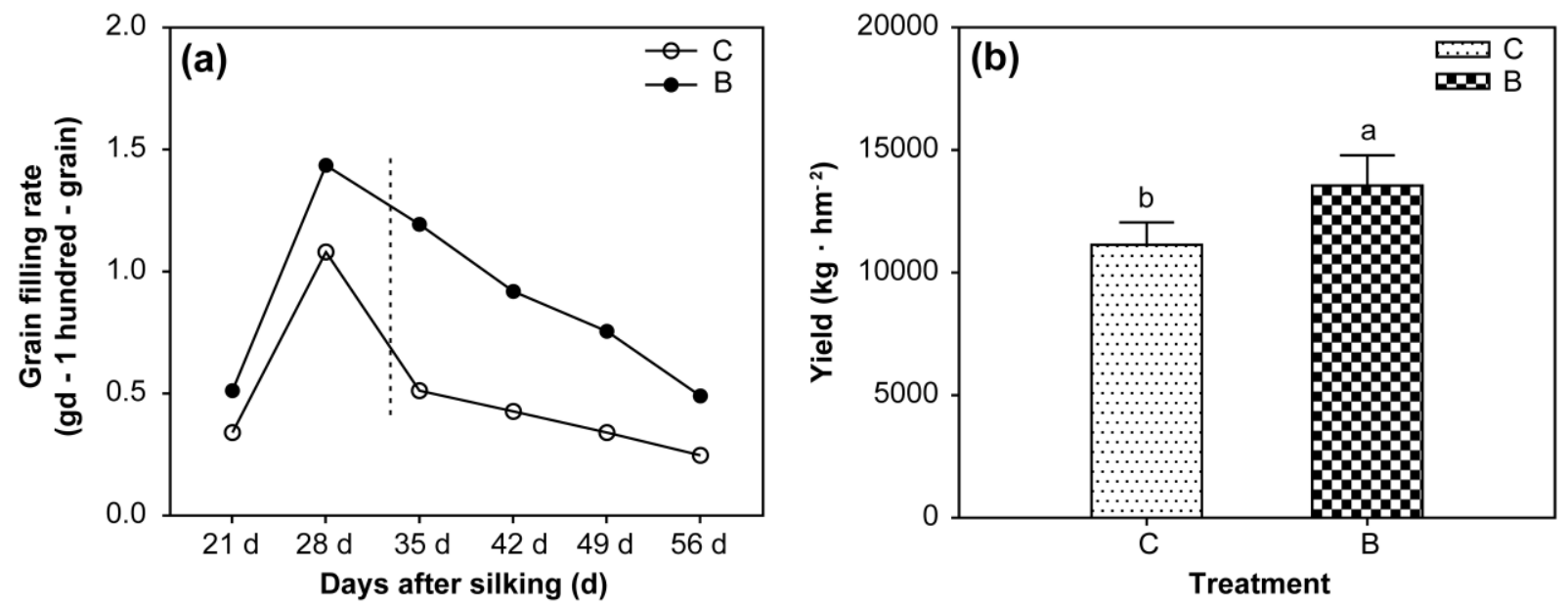

Fig. 2. Effects of biochar addition on (a) the grain filling rate and (b) the maize yield. Different letters indicate significant differences (paired t-test, $P<0.05$ ). Here, $21 \mathrm{~d}$ is August 27 th while $56 \mathrm{~d}$ is October 1st. The vertical dashed line (---) shown in (a) represents the sampling time for M9. 


\section{Response of the Soil Bacterial Community Composition to Biochar Addition}

As shown by the high-throughput sequencing analysis, the predominant bacteria in soil samples included Proteobacteria with an average relative abundance of $34.41 \%$, Acidobacteria with an average relative abundance of $20.79 \%$, Actinobacteria with an average relative abundance of $16.75 \%$, Chloroflexi with an average relative abundance of $10.11 \%$, Gemmatimonadetes with an average relative abundance of $6.21 \%$, Bacteroidetes with an average relative abundance of $4.82 \%$, Patescibacteria with an average relative abundance of $1.25 \%$, Planctomycetes with an average relative abundance of $0.88 \%$, and Nitrospirae with an average relative abundance of $0.71 \%$. For samples collected from the M7 period, compared to treatment $\mathrm{C}$, treatment $\mathrm{B}$ provided significant enhancement in the relative abundance of Proteobacteria (Fig. 3a), Actinobacterial (Fig. 3c), Bacteroidetes (Fig. 3f), and Patescibacteria (Fig. 3g). For samples collected from the M9 period, treatment $\mathrm{B}$ provided significant enhancement in the relative abundance of Proteobacteria (Fig. 3a), Bacteroidetes (Fig. 3f), Patescibacteria (Fig. 3g), and Nitrospirae (Fig. 3i), compared to treatment $\mathrm{C}$. In addition, the relative abundance of Gemmatimonadetes (Fig. 3e) was found to be higher in the sample from treatment B than that from treatment $\mathrm{C}$. However, treatment $\mathrm{C}$ provided a higher relative abundance of Planctomycetes (Fig. $3 \mathrm{~h}$ ) in samples collected from both M7 and M9 than treatment B. A similar trend was also observed in the relative abundance of Acidobacteria (Fig. 3b) in the sample collected from the M9 period. These findings suggested that the microbial abundance of saline-alkali soil was very sensitive to biochar addition.
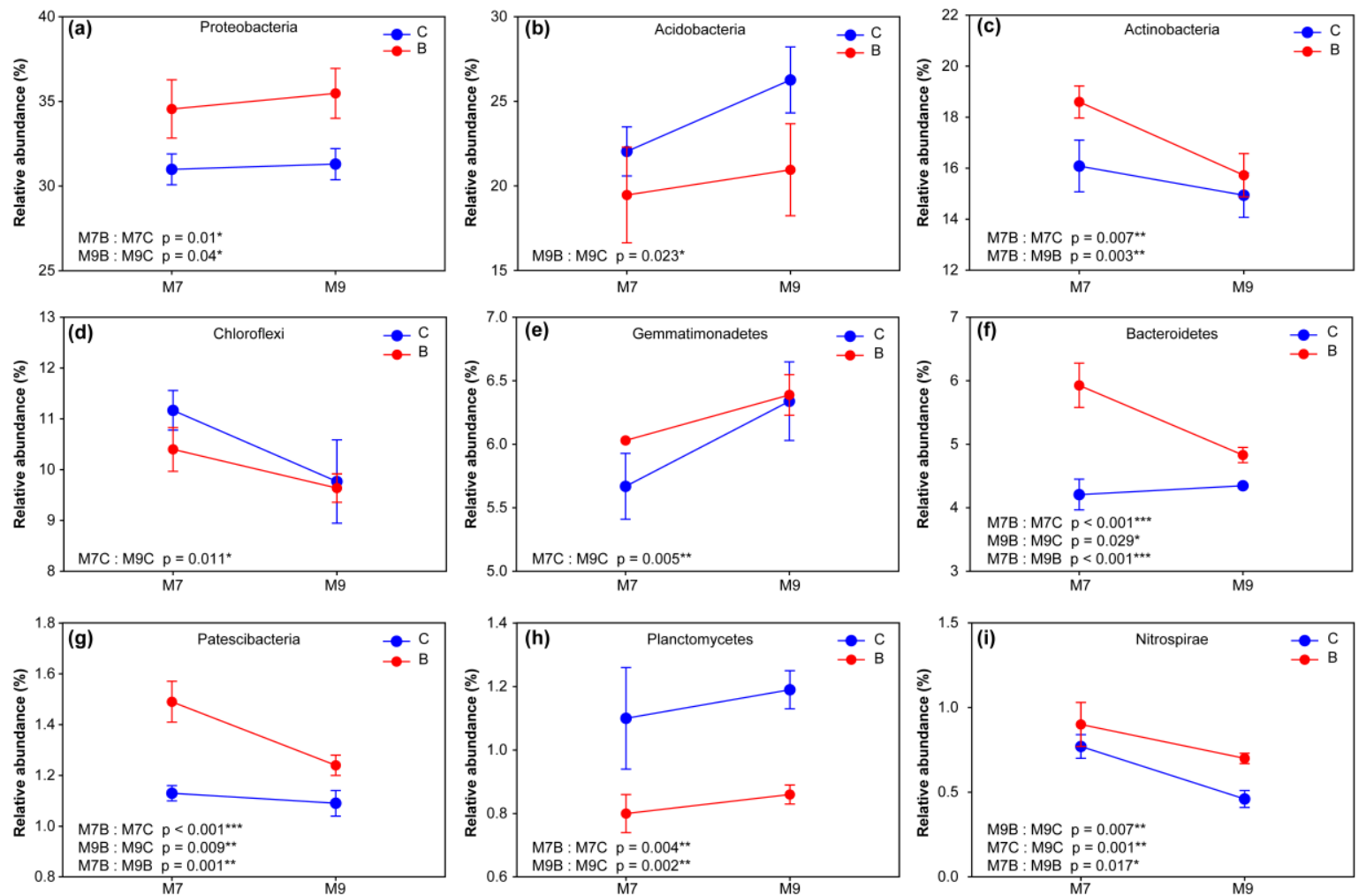

Fig. 3. Effects of biochar addition on the relative abundance of different soil microbial groups. Significance is displayed in bold, ${ }^{*} P<0.05$; ${ }^{* *} P<0.01$; ${ }^{* *} P<0.001$. Only significant treatment effects are labeled on the figure (one-way ANOVA, LSD analysis). 


\section{Response of Soil Enzyme Activity to Biochar Addition}

Most soil enzymes are secreted by microorganisms. These enzymes catalyze many biochemical reactions in the soil. Therefore, part of the ecological function of the soil microbial community is realized by enzymes (Jiang 2016). In this study, treatment B provided higher DHA activity (Fig. 4a), BG activity (Fig. 4b), and Alka PME activity (Fig. 4d) in samples collected from the M7 and M9 period than treatment C. However, the NAG activity (Fig. 4c) was insignificant in samples processed from either treatment. Comparing the variations between the M7 and M9 periods, it was found that the DHA and BG activity were lower during the M7 period than the M9 period, while the Alka PME and NAG activity were greater during the M7 period than the M9 period. This result demonstrated that biochar addition (even after waterlogging) increased the activity of enzymes associated with organic degradation and the secretion of carbon, nitrogen, and phosphorus from microbials in the soil. Such enhanced enzyme activity allowed the soil microorganisms to achieve improved nutrient transformation.
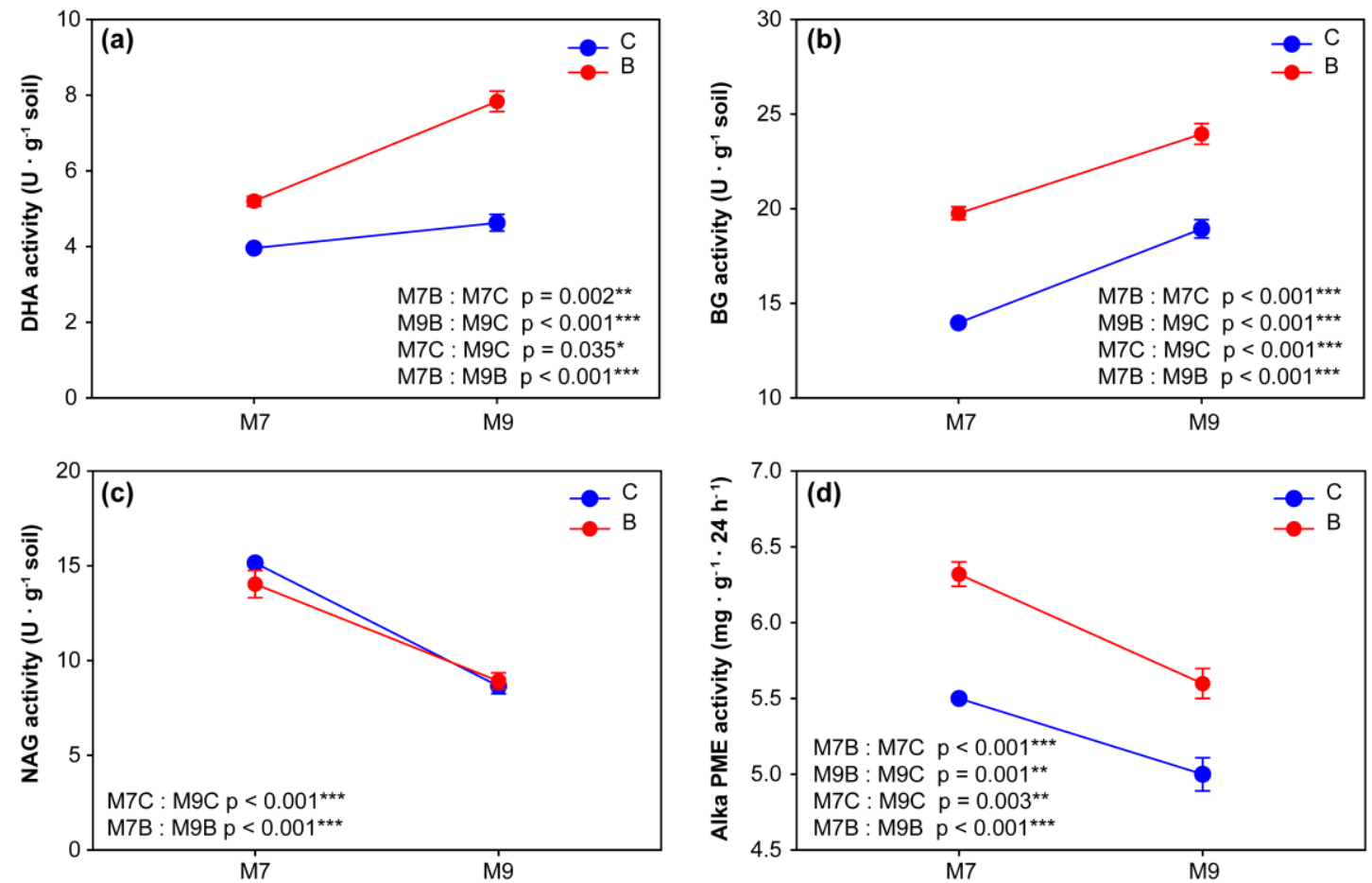

Fig. 4. Effects of biochar addition on different soil enzyme activity. Asterisks indicate significant effects, ${ }^{*} P<0.05 ;{ }^{* *} P<0.01 ;{ }^{* * *} P<0.001$. Only the significant treatment effects are labeled on the figure (one-way ANOVA, LSD analysis).

\section{Driving Factors for Changes in Soil Bacterial Community Structure and Overall Pattern of Soil Enzyme Activity}

As shown by the RDA analysis of environmental factors $(\mathrm{pH}$, moisture, bulk density, WSAR, BR, SOC, AN, and AP) on soil bacterial community structure, the two axes explained $77.7 \%$ of the structural variation in the bacterial community (Fig. 5). AN, AP, SOC, WSAR, and BR, along with biochar addition M7B and M9B, were all distributed in the negative direction of the first axis, while $\mathrm{pH}$, bulk density, and moisture, along with M7C and M9C treatments, were distributed in the positive direction of the first axis. The M7B and M9B treatments were found to be quite clustered, while the M7C and M9C 
treatments were quite scattered. This feature suggested that the samples processed from treatment $B$ were relatively stable and suffered from little variation after waterlogging. The constrained $\mathrm{P}$ test showed that AN, AP, WSAR, and SOC contributed to significant variation in the bacterial community structure. They explained $52.5 \%, 44.7 \%, 44.7 \%$, and $41.0 \%$ of the entire bacterial community variation, respectively. In addition, $\mathrm{pH}$ and moisture were found to have a substantial impact on the variation of bacterial community structure. These findings suggested that the bacterial community structure was very sensitive to the soil environment, and soil nutrients exhibited a particularly high level of explanatory power in relation to the bacterial community.
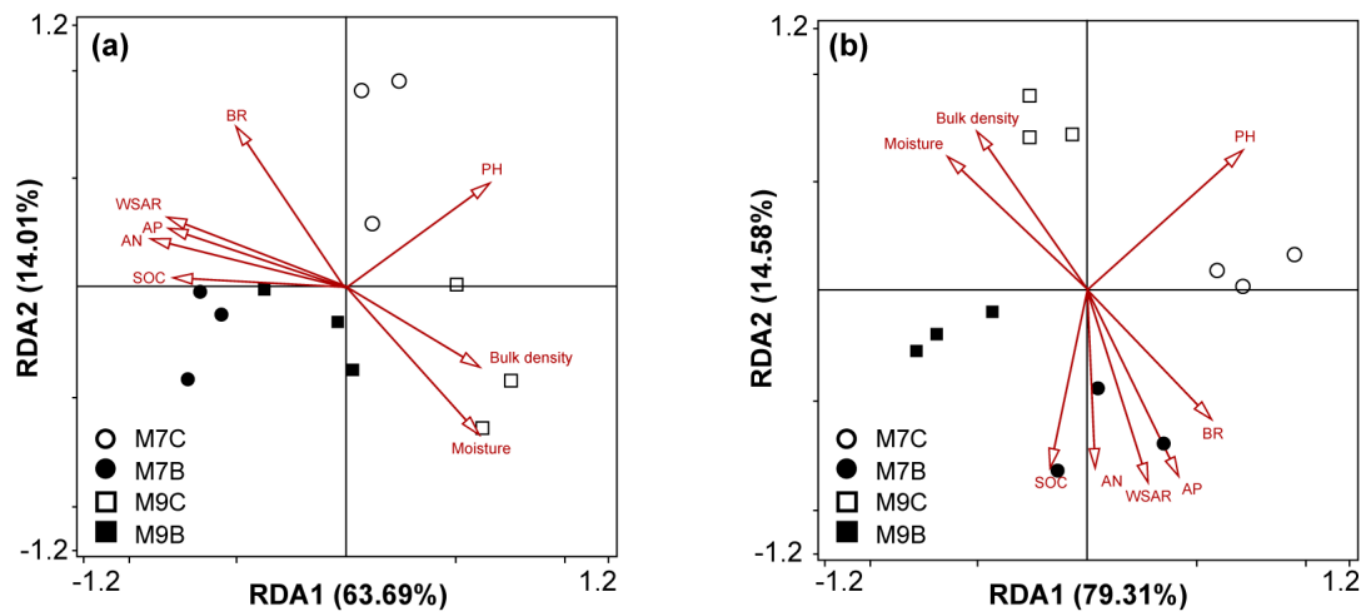

\begin{tabular}{lccc}
\hline (c) $\begin{array}{c}\text { Factor } \\
\text { and } \\
\text { vectors }\end{array}$ & \multicolumn{3}{c}{$\begin{array}{c}\text { Soil bacteria phylum } \\
\text { community structure }\end{array}$} \\
\cline { 2 - 4 } & $\%$ & $\mathrm{~F}$ & $\mathrm{P}$ \\
\hline AN & 52.5 & 11.1 & $0.002^{\star \star}$ \\
AP & 44.7 & 8.1 & $0.004^{\star \star}$ \\
WSAR & 44.7 & 8.1 & $0.002^{\star \star}$ \\
SOC & 41.0 & 7.0 & $0.002^{\star \star}$ \\
pH & 33.5 & 5.0 & $0.024^{\star}$ \\
Moisture & 30.4 & 4.4 & $0.020^{\star}$ \\
Bulk density & 27.4 & 3.8 & 0.054 \\
BR & 24.2 & 3.2 & 0.052 \\
\hline
\end{tabular}

\begin{tabular}{lccc}
\hline (d) $\begin{array}{c}\text { Factor } \\
\text { and } \\
\text { vectors }\end{array}$ & \multicolumn{3}{c}{ Soil enzymatic activities } \\
\cline { 2 - 4 } & $\%$ & $\mathrm{~F}$ & $\mathrm{P}$ \\
\hline $\mathrm{pH}$ & 47.0 & 8.9 & $0.010^{\star}$ \\
Moisture & 38.2 & 6.2 & $0.016^{\star}$ \\
BR & 30.6 & 4.4 & $0.044^{\star}$ \\
Bulk density & 28.5 & 4.0 & 0.058 \\
AP & 24.3 & 3.2 & 0.064 \\
WSAR & 18.6 & 2.3 & 0.136 \\
SOC & 12.0 & 1.4 & 0.250 \\
AN & 10.0 & 1.1 & 0.326 \\
\hline
\end{tabular}

Fig. 5. Ordination bi-plots based on the redundancy analysis (RDA) of bacterial community composition (dominant bacterial phylum data) (a) and soil enzymatic activities (b). The contribution and significance of different variables to the variation in the overall bacterial community composition (c) and soil enzymatic activity (d) was tested by Monte Carlo permutations. ${ }^{*} P<0.05,{ }^{* \star} P<0.01$. The significant $P$ values are displayed in bold.

As shown by the RDA analysis of the soil environmental factors ( $\mathrm{pH}$, moisture, bulk density, WSAR, BR, SOC, AN, and AP) on the soil enzymes, the two axes explained 93.89\% of the variation in the soil enzymes. The M7C and M9C treatments were located quite far away from each other and accompanied by a large variation on the first axis. However, both treatments were distributed in the positive direction of the second axis. 
The soil environmental factors $-\mathrm{pH}$, moisture, and bulk density - were positively correlated with these treatments. The M7B and M9B treatments were located quite close to each other on the first axis, along with a small difference. Both of these two treatments were distributed in the negative direction of the second axis. The soil AN, AP, SOC, WSAR, and BR were positively correlated with these two treatments. These results indicated that the samples processed from treatment B experienced a smaller variation during both periods and were more stable than those processed from treatment $\mathrm{C}$. The constrained $\mathrm{P}$ test showed that only $\mathrm{pH}$, moisture, and $\mathrm{BR}$ had significant effects on soil enzyme activity. These factors explained $47.0 \%, 38.2 \%$, and $30.6 \%$ of the variation in enzyme activity, respectively. The findings suggested that the soil enzyme activity was sensitive to the physical properties of the soil.

\section{Relationship between the Relative Abundance of Specific Bacterial Groups, Soil Enzyme Activity, Soil Parameters, and Plant Traits}

As shown in Table 2, during the M9 period, the relative abundances of Bacteroidetes and Nitrospirae in soil had a significant negative correlation with soil $\mathrm{pH}$, while the relative abundance of Planctomycetes had a significant positive correlation with soil pH. In addition, the relative abundances of Proteobacteria, Bacteroidetes, Patescibacteria, and Nitrospirae had significant negative correlations with soil moisture and a significant positive correlation with WSAR. However, the relative abundance of Planctomycetes had a significant negative correlation with WSAR.

The relative abundance of Nitrospirae had a significant positive correlation with $\mathrm{BR}$, while the relative abundance of Planctomycetes had a significant negative correlation with BR. In terms of the correlations between the relative abundances of dominant bacteria in soil and the soil nutrients, the relative abundances of Bacteroidetes and Nitrospirae had significant positive correlations with SOC, AN, and AP contents, while the relative abundance of Planctomycetes had a significant negative correlation with these three nutrients. In terms of the correlation between the soil microorganisms and the plant traits, the relative abundances of Proteobacteria, Bacteroidetes, and Nitrospirae showed strong or very significant positive correlations with root biomass, root activity, plant biomass, mean grain filling rate, and yield. On the other hand, the relative abundances of Acidobacteria and Planctomycetes had a negative or significantly negative correlation with the plant traits.

The DHA, BG, and PME activities in the soil had significant negative correlations with $\mathrm{pH}$, but significant positive correlations with BR. The DHA and BG activities had significant positive correlations with WSAR. The BG and PME activities had significant positive correlations with SOC and AP. The DHA activity had significant positive correlations with SOC, AN, and AP. Meanwhile, the DHA, BG, and PME activities had significant positive correlations with root biomass, root activity, plant biomass, and mean grain filling rate. However, only the DHA activity showed a significant positive correlation with yield.

As shown by the correlation analysis between maize yield and soil micro-ecological environment indicators (Fig. 6), maize yield had significant positive correlations with the relative abundances of Proteobacteria, Bacteroidetes, and Nitrospirae in the soil as well as the DHA activity, AN content, and WSAR. 
Table 2. Pearson's Correlations between the Relative Abundances of Dominant Microbial Groups, Soil Enzymatic Activities, and Soil Parameters

\begin{tabular}{|c|c|c|c|c|c|c|c|c|c|c|c|c|c|}
\hline Microbial groups & $\mathrm{pH}$ & Moisture & $\begin{array}{l}\text { Bulk } \\
\text { density }\end{array}$ & WSAR & $\mathrm{BR}$ & SOC & AN & AP & $\begin{array}{c}\text { Root } \\
\text { biomass }\end{array}$ & $\begin{array}{l}\text { Root } \\
\text { activity }\end{array}$ & $\begin{array}{c}\text { Plant } \\
\text { biomass }\end{array}$ & $\begin{array}{c}\text { Mean } \\
\text { grain filling } \\
\text { rate }\end{array}$ & Yield \\
\hline Proteobacteria & -0.785 & $-0.950^{\star *}$ & -0.659 & $0.830^{*}$ & 0.725 & 0.793 & $0.883^{*}$ & 0.732 & $0.907^{\star}$ & $0.873^{*}$ & $0.828^{*}$ & $0.907^{*}$ & $0.834^{*}$ \\
\hline Acidobacteria & 0.735 & $0.902^{*}$ & 0.478 & -0.705 & -0.657 & -0.719 & $-.897^{\star}$ & -0.624 & $-0.892^{*}$ & -0.809 & -0.704 & $-0.825^{\star}$ & $-0.838^{*}$ \\
\hline Actinobacteria & -0.449 & -0.674 & -0.219 & 0.478 & 0.356 & 0.417 & 0.775 & 0.193 & 0.696 & 0.611 & 0.319 & 0.549 & 0.670 \\
\hline Chloroflexi & -0.195 & 0.157 & 0.652 & -0.352 & 0.230 & 0.141 & 0.281 & -0.028 & 0.045 & 0.007 & -0.206 & -0.053 & 0.017 \\
\hline Gemmatimonadetes & 0.218 & -0.177 & -0.481 & 0.177 & -0.277 & -0.182 & -0.339 & 0.102 & -0.051 & -0.137 & 0.203 & -0.017 & 0.016 \\
\hline Bacteroidetes & $-0.866^{*}$ & $-0.922^{* *}$ & -0.688 & $0.874^{*}$ & 0.808 & $0.847^{*}$ & $0.886^{*}$ & $0.816^{*}$ & $0.936^{* *}$ & $0.914^{*}$ & $0.898^{*}$ & $0.951^{* *}$ & $0.864^{*}$ \\
\hline Patescibacteria & -0.661 & $-0.871^{*}$ & $-0.874^{*}$ & $0.868^{*}$ & 0.613 & 0.693 & 0.601 & 0.786 & 0.751 & 0.745 & $0.898^{*}$ & $0.836^{*}$ & 0.694 \\
\hline Planctomycetes & $0.983^{* \star}$ & 0.738 & 0.646 & $-0.907^{*}$ & $-0.935^{\star \star}$ & $-0.891^{*}$ & $-0.878^{*}$ & $-0.851^{*}$ & $-0.933^{\star \star}$ & $-0.969^{\star *}$ & $-0.916^{*}$ & $-0.967^{\star *}$ & $-0.858^{*}$ \\
\hline Nitrospirae & $-0.877^{*}$ & $-0.929^{* *}$ & -0.715 & $0.901^{*}$ & $0.843^{*}$ & $0.888^{*}$ & $0.921^{* *}$ & 0.809 & $0.922^{* *}$ & $0.949^{* *}$ & $0.895^{*}$ & $0.974^{\star *}$ & $0.823^{*}$ \\
\hline \multicolumn{14}{|l|}{ Enzymes groups } \\
\hline $\mathrm{DHA}$ & $-0.901^{*}$ & -0.808 & -0.731 & $0.933^{* *}$ & $0.822^{*}$ & $0.812^{*}$ & $0.821^{*}$ & $0.820^{*}$ & $0.941^{* \star}$ & $0.929^{\star \star}$ & $0.924^{\star \star}$ & $0.948^{\star \star}$ & $0.892^{*}$ \\
\hline$B G$ & $-0.921^{* *}$ & -0.688 & -0.778 & $0.935^{* *}$ & $0.899^{*}$ & $0.865^{\star}$ & 0.732 & $0.887^{*}$ & $0.825^{\star}$ & $0.911^{*}$ & $0.955^{* *}$ & $0.936^{* *}$ & 0.740 \\
\hline NAG & 0.116 & -0.622 & -0.508 & 0.213 & -0.105 & 0.116 & 0.040 & 0.235 & 0.097 & 0.040 & 0.293 & 0.194 & 0.059 \\
\hline PME & $-0.907^{\star}$ & -0.740 & -0.502 & 0.718 & $0.871^{*}$ & $0.853^{*}$ & 0.792 & $0.888^{*}$ & $0.844^{*}$ & $0.816^{*}$ & $0.874^{*}$ & $0.871^{*}$ & 0.777 \\
\hline
\end{tabular}

The values are correlation coefficients. ${ }^{*} \mathrm{P}<0.05 ;{ }^{* *} \mathrm{P}<0.01$. Soil variables that showed no significant correlations with any microbial and enzyme parameters were not included in this table. 


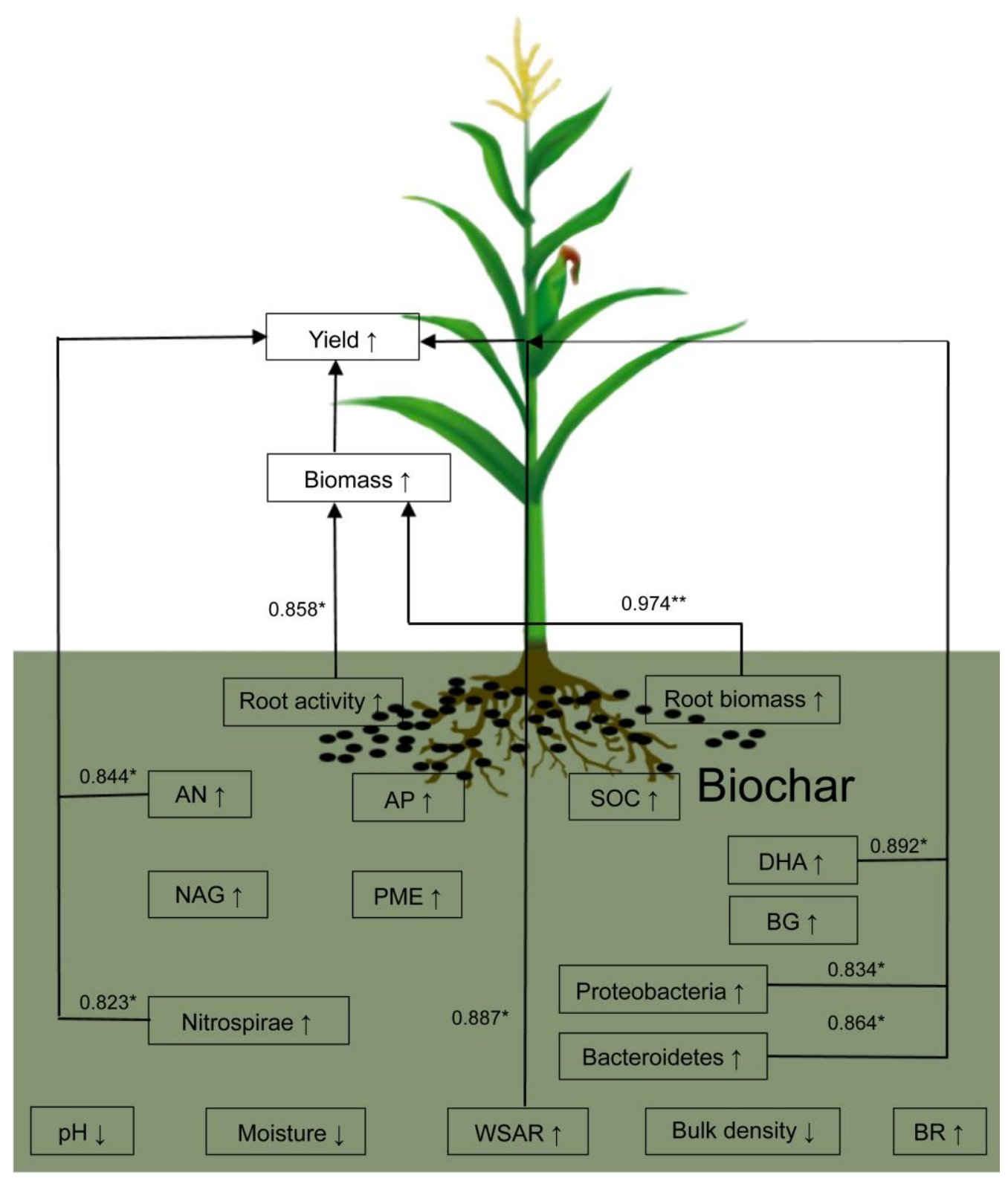

Fig. 6. Response of soil microecological environment and maize yield to biochar addition

\section{Biochar Addition Changes the Physico-Chemical Properties of Soil Which Facilitates Further Variation in the Structure and Function of Soil Microbial Communities}

Biochar addition altered the structure of the saline-alkali soil, significantly reducing bulk density. Simultaneously, biochar addition improved soil chemical properties, reduced saline-alkali soil $\mathrm{pH}$, and increased soil SOC, AN, and AP. The results of a study by Wang et al. (2020) are consistent with findings where biochar promotes soil chemical properties, and these increased soil chemical variables have a significant correlation with soil microorganisms. The relative abundances of soil bacteria in different phyla demonstrated sensitive responses to biochar addition. The addition of biochar was found to increase the relative abundances of Proteobacteria, Actinobacteria, Bacteroidetes, Gemmatimonadetes, 
Patescibacteria, and Nitrospirae. Proteobacteria was the most abundant bacterial group in the rhizosphere of maize. Past studies have shown that Proteobacteria can use complex organic compounds and plant residues as carbon and nitrogen sources in agricultural soils (Spain et al. 2009). This study also showed that the relative abundance of Proteobacteria had a positive correlation with biochar. Actinobacteria can also promote the decomposition of plant debris in the soil and provide a certain function in the nitrogen cycle as a source of soil nutrients (Lauber et al. 2008). In this study, the relative abundance of Actinobacteria in the soil was also observed to increase significantly after biochar addition. This behavior may explain the increase of AN in the soil. Bacteroidetes are found in soils with a high soil organic carbon. They are the main contributors to the mineralization of organic carbon (Han 2016). The abundance of Bacteroidetes in the soil increased significantly after the addition of the carbon-rich biochar. Gemmatimonadetes are a type of probiotic and biocontrol bacteria in soil (Canbolat et al. 2006; Kolton et al. 2011). Some researchers have shown that the abundance of Gemmatimonadetes is closely related to phosphorus metabolism (Zaidi et al. 2009; Oteino et al. 2015). The current study also showed a significant increase of AP in biochar-treated soil, which may be caused by the increase in the abundance of Gemmatimonadetes. Nitrospirae play an important role in the nitrogen cycle in the soil. They can participate in the nitrification and reduce the excessive accumulation of nitrite in the soil (Daims et al. 2015). In this study, the addition of biochar increased the relative abundance of Nitrospirae in saline-alkali soils and alleviated the growth challenge for corn plants on saline-alkali soils. A study by Canfora et al. (2014) showed results consistent with findings where saline-alkali soil could produce more acidic substances under the influence of Nitrospirae. This feature helps alleviate soil salinization and alkalinization. In this study, the addition of biochar reduced the relative abundance of Acidobacteria. This may be attributed to Acidobacteria being a type of oligotrophic bacteria such that its abundance is affected by the content of organic matter in the soil (Jenkins et al. 2010).

Soil enzymes are biocatalysts present in the soil. Most soil enzymes are secreted by soil microorganisms, while a few are secreted by plant roots and soil animals. Soil enzymes can participate actively in various biochemical reaction processes in the soil (Futa et al. 2020). The activity of soil enzymes reflects the intensity of biochemical processes in the soil and represents the functions of the soil microbial community to a certain extent, while characterizing the strength of the soil nutrient conversion ability (He et al. 2015). In this study, it was found that biochar addition could significantly improve DHA, BG, and Alka PME activity in saline-alkaline soil. DHA activity reflects the number of active microorganisms in the soil system and their capability to degrade organic matter. This study shows that the DHA activity is improved significantly by biochar addition. A possible explanation is that the addition of biochar increases the soil organic matter content, which provides "food" for the survival and reproduction of microorganisms. This enriches the source of DHA enzymes in the soil (Tischer et al. 2015). BG is an important class of enzymes involved in the soil carbon cycle whose activity is positively correlated with soil organic carbon (Raiesi and Khadem 2019). It seems that the significant increase in the soil SOC content after biochar addition may be the cause of the enhanced activity of BG in the soil. Alka PME is an enzyme that catalyzes the mineralization of soil organic phosphorus compounds. The activity of Alka PME directly affects the decomposition and transformation of organic phosphorus in the soil, as well as its bioavailability (Lu et al. 2015). In this study, the addition of biochar increased the activity of Alka PME substantially, which may be the reason for the significant increase in soil AP content.

Wang et al. (2020). "Biochar \& soil waterlogging," BioResources 15(4), 9303-9323. 
As a carbon-rich substance, biochar contains a variety of nutrients. Some studies have suggested that the effective water-soluble nutrients in biochar can act on soil microorganisms and promote their growth when biochar is applied to the soil (Joseph et al. 2010; Yang et al. 2016; Li et al. 2019). Furthermore, some small molecules in biochar can function as potential regulators to change the soil microbe and soil enzyme activities (Yang et al. 2016). This study found that the structure of the soil bacterial community was very sensitive to the soil environment (Fig. 5), in particular, soil nutrients. The changes of AN, $\mathrm{AP}$, and SOC in the soil provide substantial driving forces for structural changes in bacterial communities. The changes in the physical condition of the soil caused by biochar, such as WSAR, pH, and moisture, can also significantly affect the variation in the structure of the soil bacterial community. Soil $\mathrm{pH}$, moisture, and BR are also some of the most important soil parameters associated with the changes in the soil enzyme activity pattern. Therefore, the main contribution of biochar is to improve the properties of saline-alkali soil. Specifically, the addition of biochar makes soil looser and more porous, which reduces the level of compaction, increases permeability, and increases the levels of nutrients. The integration of biochar and soil provides a space for the survival of microorganisms. Meanwhile, the good soil water, heat, and gas environment, along with the rich energy supply, greatly promote the growth, development, and metabolism of microbes, all of which further improve the activity of enzymes secreted from microbes and accelerate the associated biochemical reactions. Such a chain of outcomes provides abundant energy for crop growth (Zheng et al. 2016; Yao et al. 2017). This conclusion is consistent with the hypothesis that the change in the structure of the soil microbial community is indirectly driven by the change in rhizosphere soil properties.

\section{Biochar Addition Provides More Stable Soil Properties, Microbial Community Structure, and Microbial Function After Waterlogging, Thereby Enabling Smooth Grain-Filling and Increased Maize Yield}

Soil with biochar exhibits good water permeability, highly stable water-stable aggregates, and a strong soil respiration performance even after waterlogging. Sufficient oxygen is provided to the plant roots to ensure normal metabolic activities (Liu 2020).

After the occurrence of waterlogging, the respiration process of saline-alkali soils is hindered, which further suppresses the activity of eutrophic microorganisms. Therefore, the decomposition of organic matter and the conversion of available nutrients in the soil are impeded (Han and Zhou 2011; Yu 2019). Waterlogging causes nitrate-nitrogen leaching in the soil and intensifies the denitrification effect at the same time. However, the addition of biochar in the soil can alleviate such behavior because of the high relative abundance of Nitrospirae and the high AN content. In this study, the relative abundances of Proteobacteria and Bacteroidetes were still maintained at a high level in the soil after waterlogging because of the alleviation effect from biochar addition. These relative abundances also showed a significant positive correlation with the WSAR, SOC, AN, and AP content in the soil. Similarly, the activities of enzymes (e.g., DHA, BG, and Alka PME) secreted from the microbes remained quite high in the soil with biochar addition after waterlogging. This concurs with the findings of other studies that biochar addition provides a substantial improvement to the DHA activity in soil (Yang 2015; Raiesi and Khadem 2019). These findings demonstrate that biochar addition reduces the level of disturbance in the soil from the adverse environmental conditions of waterlogging. As a consequence, the active microorganisms in the soil still remain abundant, along with a high rate of degradation of organic matter. These features provide an increased amount of relevant and 
rapidly available nutrients in the soil. Furthermore, in this study (Fig. 5) that there was a sharp change in the structure of the soil bacterial community during periods before and after waterlogging in the control. However, the structure of the bacterial community remained similar in the soil when biochar was added. This finding suggests that the addition of biochar attenuates the structural change of the soil bacterial community caused by waterlogging and, furthermore, provides stable residence and refuge opportunities to support the survival and activities of bacteria (Jiang 2016). This conclusion is consistent with the second hypothesis.

Waterlogging will often cause maize leaves to turn yellow, and the base of the stalk to turn purple-red. At the same time, the growth of the plant becomes slower or stagnates. In this study, the waterlogging disaster occurred during the grain-filling stage of the maize. The excessive water content in the soil hindered the plants' respiration performance and reduced the vitality of maize roots. These issues resulted in a small biomass of plants both underground and above-ground as well as a slow grain-filling rate, both of which severely affected the maize yield (Table 1 and Fig. 2). Similar conclusions are drawn in other studies (Zhou et al. 2012; Ren et al. 2013). However, the addition of biochar can alleviate the growth suppression effects of waterlogging on the soil and maintain stable growth and strong vitality in maize roots. Thus, biochar ensures the proper growth of plants and a consistent grain-filling process, providing an improvement in the maize yield (Li 2018). In this study, the maize yield showed a significant positive correlation with the relative abundances of Proteobacteria, Bacteroidetes, and Nitrospirae, DHA activity, AN content, and WSAR in the soil. These correlations indicate that the addition of biochar can provide a healthy and stable micro-ecological environment in saline-alkali soils, which lays the foundation for an increased maize yield.

\section{CONCLUSIONS}

1. Biochar addition reduces $\mathrm{pH}$, lower bulk density, higher soil organic carbon, increased available nitrogen and available phosphorus, greater relative abundance of eutrophic bacteria, and stronger activities of microbial secretase in the soil.

2. The overall pattern of soil enzymes is affected by biochar addition through changes in the physical properties ( $\mathrm{pH}$, moisture, and soil respiration (BR)) of the soil.

3. The structure of soil bacterial communities is more sensitive to soil nutrients (available nitrogen (AN), available phosphorus (AP), and soil organic carbon (SOC)) and waterstable aggregate stability rate (WSAR).

4. After the occurrence of waterlogging, applying biochar can provide the soil with better water permeability, higher WSAR, stronger soil respiration performance, higher abundance of soil bacteria, and a relatively higher level of enzyme activity.

5. These improvements result in vigorous plant growth, a high grain-filling rate, and ultimately a high yield.

6. The addition of biochar can regulate the micro-ecological environment in saline-alkali soil; enhance its agricultural function through improvements in soil microorganisms, soil enzymes, and soil nutrients; and improve the growth and yield of maize. The ability of biochar to address agricultural issues caused by sudden waterlogging disasters makes it a valuable addition for saline-alkali soils. 


\section{ACKNOWLEDGEMENTS}

The authors are grateful for the support of the National Thirteenth Five-year Plan Key research and Development Project "Biochar fertilizer and microbial fertilizer research and development" (2017YFD0200803), Heilongjiang Bayi Agricultural University Support Program for San Heng San Zong (ZRCQC201909, ZRCPY201803, ZRCQC202001), Scientific Research Fund of Heilongjiang Bayi Agricultural University (XDB201803), and the Agriculture and Reclamation Bureau Project (HKKY190210).

\section{CONFLICTS OF INTEREST}

The authors declare no conflict of interest.

\section{REFERENCES CITED}

Bao, S. D. (2000). Soil Analysis. China Agriculture Press, Beijing, China.

Canbolat, M. Y., Bilen, S., Çakmakçı, R., Şahin, S., and Aydın, A. (2006). "Effect of plant growth promoting bacteria and soil compaction on barley seedling growth, nutrient uptake, soil properties and rhizosphere microflora," Biol. Fertil. Soils 42, 350-357. DOI: 10.1007/s00374-005-0034-9

Canfora, L., Bacci, G., Pinzari, F., Lo Papa, G., Dazzi, C., and Benedetti, A. (2014). "Salinity and bacterial diversity: To what extent does the concentration of salt affect the bacterial community in a saline soil," PLoS One 9, e106662. DOI: 10.1371/journal.pone.0106662

Chen, T., Zhang, Y., Fu, J., Yang, L., Chi, Y., Wu, P., Yin, X., Wang, H., Yang K., and Wang, Yu. (2020). "No-tillage increased corn yields and carbon sequestration," Agronomy Journal. 2020, 1-15. DOI:10.1002/agj2.20353

Chen, W.-F. A. (2012). "Combined biomass pellet carbonization furnace and a carbon production method thereof," China Patent No. CN 102092709.

Daims, H., Lebedeva, E. V., Pjevac, P., Han, P., Herbold, C., Albertsen, M., Jehmlich, N., Palatinszky, M., Vierheilig, J., Bulaev, A., Kirkegaard, R. H., von Bergen, M., Rattei, T., Bendinger, B., Nielsen, P. H., and Wagner, M. (2015). "Complete nitrification by Nitrospira bacteria," Nature 528, 504-509. DOI: 10.1038/nature16461

Fan, S., Zuo, J., and Dong, H. (2020). "Changes in soil properties and bacterial community composition with biochar amendment after six years," Agronomy 10(5), 746. DOI: 10.3390/agronomy 10050746

Fu, J., Xiao, Y., Wang, Y., Liu, Z., and Yang K. (2018). "Trichoderma affects the physiochemical characteristics and bacterial community composition of salinealkaline maize rhizosphere soils in the cold-region of Heilongjiang Province," Plant and Soil 436 (4), 211-227. DOI:10.1007/s11104-018-03916-8

Futa, B., Oleszczuk, P., Andruszczak, S., Kwiecinska-Poppe, E., and Kraska, P. (2020). "Effect of natural aging of biochar on soil enzymatic activity and physicochemical properties in long-term field experiment," Agronomy 10(3), 449. DOI: 10.3390/agronomy 10030449

Guan, S. (1986). Soil Enzyme and its Research Methods, Agriculture Press, Beijing, China. 271-319. 
Guo, T. (2018). Effects of Short-term Tillage and Fertilization on Enzyme Activities and Bacterial Diversity of Meadow Black Soil, Master's Thesis, Northeast Agricultural University, Haerbin, China. (in Chinese with English abstract)

Han, G. and Zhou, L. (2011). Improvement and Utilization of Saline Soil in Heilongjiang, Agriculture Press, Beijing, China.

Han, G. (2016). Effect of Biochar on Soil Physicochemical Property and Microbial Diversity in Different Soil Types, Master's Thesis, Shenyang Agricultural University, Shenyang, China. (in Chinese with English abstract)

He, F., Wang, H., Chen, Q., Yang, B., Gao, Y., and Wang, L. (2015). "Short-term response of soil enzyme activity and soil respiration to repeated carbon nanotubes exposure," Soil Sediment Contam. 24(3), 250-261. DOI:

10.1080/15320383.2015.948611

Jenkins, S. N., Rushton, S. P., Lanyon, C. V., Whiteley, A. S., Waite, I. S., Brookes, P. C., Kemmitt, S., Evershed, R. P., and O’Donnell, A. G. (2010). "Taxon-specific responses of soil bacteria to the addition of low level C inputs," Soil Biol. Biochem. 42, 1624-1631. DOI: 10.1016/j.soilbio.2010.06.002

Jiang, L. (2016). The Effect of Biochar on Soil Microbial Diversity and Community Structure, Master's Thesis, Shenyang Agricultural University, Shenyang, China.

Joseph, S. D., Camps-Arbestain, M., Lin, Y., Munroe, P., Chia, C. H., Hook, J., van Zwieten, L., Kimber, S., Cowie, A., Singh, B. P., Lehmann, J., Foidl, N., Smernik, R. J., and Amonette, J. E. (2010). "An investigation into the reactions of biochar in soil," Soil Res. 48(7), 501-515. DOI: 10.1071/SR10009

Kolton, M., Harel, Y. M., Pasternak, Z., Graber, E. R., Elad, Y., and Cytryn, E. (2011). "Impact of biochar application to soil on the root-associated bacterial community structure of fully developed greenhouse pepper plants," Appl. Environ. Microbiol. 77, 4924-4930. DOI: 10.1128/AEM.00148-11

Laboratory of Soil Physics, Nanjing Institute of Soil, Chinese Academy of Sciences. (1978). Method for Determination of Soil Physical Properties, Science Press, Beijing, China.

Lauber, C. L., Strickland, M. S., Bradford, M. A., and Fierer, N. (2008). "The influence of soil properties on the structure of bacterial and fungal communities across land-use types," Soil Biol. Biochem. 40(9), 2407-2415. DOI: 10.1016/j.soilbio.2008.05.021

Lehmann, J., Rillig, M. C., Thies, J., Maliello, C. A., Hockaday, W. C., and Crowley, D. (2009). "Biochar effects on soil biota-A review," Soil Biol. Biochem. 43(9), 18121836. DOI: 10.1016/j.soilbio.2011.04.022

Li, J. (2017). Research on Soil Quality and Production Capability under Rotation Tillage on Maize Field in Weibei Highland, Master's Thesis, Northwest Agricultural and Forestry University, Shanxi, China.

Li, Y. (2018). Effects of Biochar on Water Retention Curve and Soil Nutrients Leaching, Master's Thesis, Chinese Academy of Sciences, Guiyang, China.

Li, Y., Yang, Y., Shen, F., Tian, D., Zeng, Y., Yang, G., Zhang, Y., and Deng, S. (2019). "Partitioning biochar properties to elucidate their contributions to bacterial and fungal community composition of purple soil," Sci. Total Environ. 648, 1333-1341. DOI: 10.1016/j.scitotenv.2018.08.222

Liu, D. (2020). Effects of Biochar on Soil Microecology and Soybean Growth in Salinealkali Farmland, Doctor's Thesis, Heilongjiang Bayi Agricultural University, Daqing, China.

Lu, H. F., Lashari, M. S., Liu, X. Y., Ji, J., Li, L., Zheng, J., Kibue, G. W., Joseph, S., and 
Pan, G. (2015). "Changes in soil microbial community structure and enzyme activity with amendment of biochar-manure compost and pyroligneous solution in a saline soil from Central China," Eur. J. Soil Biol. 70, 67-76. DOI:

10.1016/j.ejsobi.2015.07.005

Meng, J., He, T., Sanganyado, E., Lan, Y., Zhang, W., Han, X., and Chen, W. (2019). "Development of the straw biochar returning concept in China," Biochar 1, 139-149. DOI: $10.1007 / \mathrm{s} 42773-019-00019-0$

Oteino, N., Lally, R. D., Kiwanuka, S., Lloyd, A., Ryan, D., Germaine, K. J., and Dowling, D. N. (2015). "Plant growth promotion induced by phosphate solubilizing endophytic Pseudomonas isolates," Front. Microbiol. 6, 745. DOI: 10.3389/fmicb.2015.00745

Quilliam, R. S., Glanville, H. C., Wade, S. C., and Jones, D. L. (2013). "Life in the 'charosphere' - does biochar in agricultural soil provide a significant habitat for microorganisms," Soil Biol. Biochem. 65, 287-293. DOI:

10.1016/j.soilbio.2013.06.004

Raiesi, F. and Khadem, A. (2019). "Short-term effects of maize residue biochar on kinetic and thermodynamic parameters of soil $\beta$-glucosidase," Biochar 1, 213-227. DOI: $10.1007 / \mathrm{s} 42773-019-00016-3$

Ren, B., Zhang, J., Li, X., Fan, X., Dong, S., Zhao, B., and Liu, P. (2013). "Effect of waterlogging on grain filling and quality of summer maize," Scientia Agricultura Sinica 46, 4435-4445.

Spain, A. M., Krumholz, L. R., and Elshahed, M. S. (2009). “Abundance, composition, diversity and novelty of soil proteobacteria," ISME 3, 992-1000. DOI: 10.1038/ismej.2009.43

Tischer, A., Blagodatskaya, E., and Hamer, U. (2015). "Microbial community structure and resource availability drive the catalytic efficiency of soil enzymes under land -use change conditions," Soil Biol. Biochem. 89, 226-237. DOI:

10.1016/j.soilbio.2015.07.011

Wang, Q., Liu, F., Chang, B., Ken, A., Liu, Y., Jiang, H., and Jiao, F. (2018). "Long-term effect of deep application of rice husk improving physical and chemical properties of soda alkaline soil," Trans. Chinese Soc. Agric. Eng. 34, 147-152. DOI:

10.11975/j.issn.1002-6819.2018.02.020

Wang, W., Wang, Z., Yang, K., Wang, P., Wang, H., Guo, L., Zhu, S., Zhu, Y., and He, X. (2020). "Biochar application alleviated negative plant-soil feedback by modifying soil microbiome," Frontiers in Microbiology 11,1-16. DOI: 10.3389/fmicb.2020.00799

Wang, Z., Tang, C., Wang, H., Zhao, C., Yin, D., Yuan, Y., Yang, K., and Li, Z. (2019). "Effect of different amounts of biochar on meadow soil characteristics and maize yields over three years," BioResources 14(2), 4194-4209. DOI:

10.15376/biores. 14.2.4194-4209

Wang, Z. Q., Zhu, S. Q., and Yu, R. P. (1993). Saline Soil in China, Science Press, Beijing, China.

Yang, F. (2015). Biochar to Combat Soil Salinization in Kashgar Oasis, Xinjiang, West China, Master's Thesis, Chinese Academy of Sciences, Beijing, China.

Yang, X., Liu, J., McGrouther, K., Huang, H., Lu, K., Guo, X., He, L., Lin, X., Che, L., Ye, Z., and Wang, H. (2016). "Effect of biochar on the extractability of heavy metals (Cd, $\mathrm{Cu}, \mathrm{Pb}$, and $\mathrm{Zn}$ ) and enzyme activity in soil," Environ. Sci. Pollut. Res. 23, 974984. DOI: $10.1007 / \mathrm{s} 11356-015-4233-0$ 
Yao, Q. (2017). Effect of Biochar Addition on Soil Physicochemical Properties and Microbial Diversity in a Black Soil of Northeast China, Master's Thesis, University of Chinese Academy of Sciences, Haerbin, China.

Yao, Q., Liu, J., Yu, Z., Li, Y., Jin, J., Liu, X., and Wang, G. (2017). “Changes of bacterial community compositions after three years of biochar application in a black soil of northeast China," Appl. Soil Ecol. 113, 11-21. DOI:

10.1016/j.apsoil.2017.01.007

Yu, B. (2019). Research on the Diversity of Microbial Community in Different SalineAlkaline Soil Ecosystems in Chain, Master's Thesis, Jiangsu University, Jiangsu, China.

Zaidi, A., Khan, M. S., Ahemad, M., and Oves, M. (2009). "Plant growth promotion by phosphate solubilizing bacteria," Acta Microbiologicaet Immunologica Hungarica 56, 263-284. DOI: 10.1556/amicr.56.2009.3.6

Zheng, J. F., Chen, J. H., Pan, G. X., Liu, X., Zhang, X., Li, L., Bian, R., Cheng, K., and Zheng, J. (2016). "Biochar decreased microbial metabolic quotient and shifted community composition four years after a single incorporation in a slightly acid rice paddy from southwest China," Sci. Total Environ. 571, 206-217. DOI: 10.1016/j.scitotenv.2016.07.135

Zhou, X., Han, H., Li, C., Guo, S., Guo, D., and Cheng, J. (2012). "Effects of waterlogging at grain filling stage on corn yield, nitrogen and phosphorus leaching loss," Trans. Chinese Soc. Agric. Eng. 28, 99-103. DOI: 10.3969/j.issn.10026819.2012.14.016

Zhu, G., Ren, Z., Zhou, G., and Ismail, A. M. (2019). "The physiological mechanism of tillering inhibition in rice by semi-submerged waterlogging and the effect on rice yield," in: Annual Meeting of Soil Science Society of China, Zhejiang, China, p. 322.

Article submitted: June 9, 2020; Peer review completed: September 27, 2020; Revised version received: October 16, 2020; Accepted: October 17, 2020; Published: October 22, 2020.

DOI: 10.15376/biores.15.4.9303-9323 